\title{
Placental cord drainage during third stage of labour: a randomized control trial at a tertiary care centre
}

\author{
Megha Chaudhary, Maitri Shah*, Nitin Makwana
}

Department of Obstetrics and Gynecology, Baroda Medical College, Vadodara, Gujarat, India

Received: 30 December 2019

Revised: 23 January 2020

Accepted: 29 January 2020

\section{*Correspondence:}

Dr. Maitri Shah,

E-mail: maitrishah.gynec@gmail.com

Copyright: () the author(s), publisher and licensee Medip Academy. This is an open-access article distributed under the terms of the Creative Commons Attribution Non-Commercial License, which permits unrestricted non-commercial use, distribution, and reproduction in any medium, provided the original work is properly cited.

\begin{abstract}
Background: Labour is a physiological process, but it is often associated with morbidity and mortality, with the most common cause being blood loss. Primary postpartum hemorrhage is commonly defined as a blood loss of $500 \mathrm{ml}$ or more within 24 hours after normal vaginal birth. A prolonged third stage of labour (more than 20 min) is associated with postpartum hemorrhage. The present study was undertaken with the objective of assessing efficacy of placental cord drainage (PCD) during active management of third stage of labour.

Methods: This is a randomized control trial in which full term primi gravida who were expected to have normal vaginal delivery, admitted in labour room of a tertiary care centre were evaluated for inclusion in the study. Total 126 participants were enrolled after having normal vaginal delivery. In study group $(n=63)$, placental cord drainage was used for management of third stage of labour while in control group $(n=63)$, third stage was managed without PCD.

Results: The mean difference in duration of third stage of labour in study and control group was 1.79 minute and the mean difference in blood loss during third stage of labour in both groups was $57.86 \mathrm{ml}$ which was statistically significant.

Conclusions: The results of this study show small positive effects from cord drainage in reducing the length of the third stage of labour and in reducing the amount of blood loss when compared with those without cord drainage. The observed changes may be of clinical significance in reducing third stage related complications.
\end{abstract}

Keywords: Active management of third stage of labour, Placental cord drainage, Postpartum hemorrhage

\section{INTRODUCTION}

Postpartum hemorrhage (PPH) is the leading direct cause of maternal mortality worldwide, and one-third of all maternal deaths in Africa and Asia can be attributed to this condition. Mortality index for PPH was $6.6 \%$ (range $0.0 \%-40.7 \%$ ) which is highest in developing and lowincome countries. ${ }^{1}$ Prevention of such life threating complication; includes diminishing its anticipated risk factors and stimulating the uterus to contract soon after delivery of fetus. ${ }^{2}$ Third stage of labor lasts longer than $20 \mathrm{~min}$ is associated with PPH. ${ }^{3}$ In routine practice, third stage of labour is managed by clamping both sides of the cord and cutting it then wait until there are signs of placental separation then deliver the placenta by controlled cord traction (Brandet Andrews Maneuver). Placental cord drainage is unclamping the cord at maternal side and releasing of placental blood to facilitate delivery of the placenta. Draining of blood from the placenta would reduce its bulkiness allowing the uterus to contract and retract effectively leading to delivery of placenta and may reduce the duration of $3^{\text {rd }}$ stage of labour. ${ }^{4}$ The present study was undertaken with the objective of assessing efficacy of placental cord drainage to reduce duration and blood loss during third stage of labour. 


\section{METHODS}

This is a Randomized control trial in which full term primi gravida who were expected to have normal vaginal delivery, admitted in labour room of a teaching hospital of central Gujarat were evaluated for inclusion in the study. Total 126 participants (required to estimate mean length in third stage of labour by taking mean difference between 2 groups by one minute with SD 4 at $95 \%$ confidence interval on $80 \%$ power by using paired t-test and unpaired t-test) were enrolled in the study over a time period of 1 year from December 2018 to November 2019.

\section{Inclusion criteria}

- $\quad$ Primi gravida with full term, singleton pregnancy

- With vertex presentation

- Expected to have spontaneous vaginal delivery.

\section{Exclusion criteria}

- Hemoglobin less than $8 \mathrm{~g} / \mathrm{dL}$

- Over distended uterus (hydramnios, multiple pregnancy, and large baby)

- Antepartum hemorrhage

- Induced labour

- Instrumental delivery

- Known coagulation disorders.

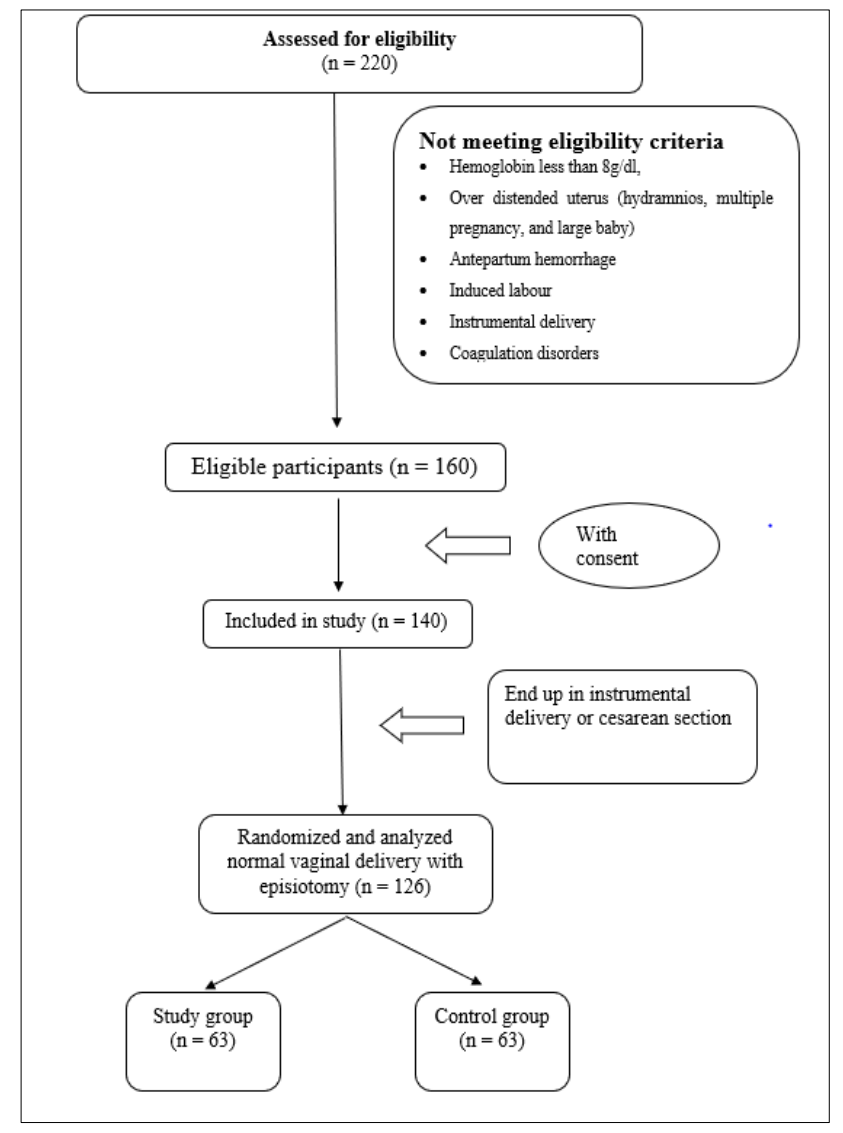

Figure 1: Recruitment of subjects in both groups.
Study procedure and intervention (Figure 1).

After noting down demographic profile of all the participants, a detailed history was taken. General and obstetric examination was done to assess gestational age, fetal presentation and status of labour at the time of admission in labour room. Baseline investigations were done for complete blood count, renal function test and liver function test were recorded.

Once the women delivered vaginally with episiotomy $(\mathrm{n}=126)$, after taking consent, they were randomized into 2 groups (study and control groups) through blind envelope method. Study cases were included in Group 1 $(\mathrm{n}=63)$ and control cases were included in Group $2(\mathrm{n}=$ 63). In the Group 1, the placental end of the cut umbilical cord unclamped immediately after it will cut and left open to drain blood in a vessel until the flow ceased. This prevented the drained blood from getting mixed with blood lost in the third stage. In the Group 2 placental end of the cut umbilical cord remained clamped. Blood lost in the third stage was collected in a clean conical drape sheet (V drape). Once the signs of placental separation seen, placenta was delivered by controlled cord traction. The duration of third stage was calculated using a stopwatch. The blood collected in the V drape sheet was measured. Mops used in episiotomy discarded. Care was taken not to mix the drained blood from the cord with the blood lost during the third stage. If placenta did not separate and an additional intervention needed to separate then patient will be excluded from the study.

The pulse rate, blood pressure and state of the uterus noted immediately after delivery. The women observed for any complications for the next one hour. All women managed according to the department protocol. Which includes 3 components of active management of third stage of labour (AMTSL).

- Injection oxytocin $10 \mathrm{IU}$ intramuscular given on anterior aspect of thigh

- Uterine massage

- Control cord traction.

Blood transfusion was given if indicated.

The duration of the third stage of labour and the amount of blood loss were the primary outcome measures whereas the incidence of $\mathrm{PPH}$, retained placenta and the need for blood transfusion will be the secondary outcome measures.

All the details were entered in excel sheet which were kept password protected. Statistical tests of significance were applied.

\section{RESULTS}

The total number of patients studied was 163 equally distributed in both the groups. The mean age of patients 
in study group was $22.02 \pm 2.13$ and in control group $22.16 \pm 1.99(\mathrm{p}=0.596)$. The mean Body Mass Index of study group was $22.69 \pm 2.58$ and in control group $21.92 \pm 1.75(\mathrm{p}=0.544) .58(92.06 \%)$ patients in study group and $56(88.89 \%)$ patients in control group took antenatal care $(\mathrm{p}=0.077)$. There was no significant difference seen in demographic profile of both the groups (Table 1).

Table 1: Demographic profile of study participants.

\begin{tabular}{|c|c|c|c|}
\hline & Study group $(n=63)$ & Control group $(n=63)$ & $p$ value $(<0.05=$ significant $)$ \\
\hline Age $($ Mean \pm SD $)$ & $22.02 \pm 2.13$ & $22.16 \pm 1.99$ & 0.596 \\
\hline \multicolumn{4}{|l|}{ ANC taken } \\
\hline Yes & $58(92.06 \%)$ & $56(88.89 \%)$ & \multirow{2}{*}{0.544} \\
\hline No & $5(7.94 \%)$ & $7(11.11 \%)$ & \\
\hline $\begin{array}{l}\text { Body mass index (BMI) } \\
\text { Mean } \pm \text { SD }\end{array}$ & $22.69 \pm 2.58$ & $21.92 \pm 1.75$ & 0.077 \\
\hline
\end{tabular}

Table 2: Gestational age of participants at delivery.

\begin{tabular}{|c|c|c|c|}
\hline Gestational age at delivery (weeks) & Group 1 & Group 2 & p value \\
\hline Sample size & 63 & 63 & \multirow{5}{*}{0.091} \\
\hline Mean \pm SD & $38.76 \pm 1.08$ & $39.11 \pm 1.22$ & \\
\hline Median & 39 & 39 & \\
\hline Min-Max & $37-41.71$ & $37-41.71$ & \\
\hline Inter quartile range & $38-39.429$ & $38.143-40$ & \\
\hline
\end{tabular}

Table 3: Haemoglobin (Hb) (gm \%) of participants during antenatal period.

\begin{tabular}{|c|c|c|c|}
\hline $\mathbf{H b}$ & Study & Control & p value \\
\hline Sample size & 63 & 63 & \multirow{5}{*}{0.254} \\
\hline Mean \pm SD & $10.5 \pm 1.22$ & $10.25 \pm 1.3$ & \\
\hline Median & 10.6 & 10.2 & \\
\hline Min-Max & $8-13.3$ & $8-13.2$ & \\
\hline Inter quartile range & $9.650-11.475$ & $9.150-11.275$ & \\
\hline
\end{tabular}

In this study, in study group, the mean gestational age at delivery was $38.76 \pm 1.08$ weeks and in control group, it was $39.11 \pm 1.22$. No significant difference in gestational age at delivery in two groups was seen $(\mathrm{p}>0.05)$ (Table 2).

In this study, in study group, the mean hemoglobin $(\mathrm{gm} \%)$ at delivery was $10.5 \pm 1.22$ and in control group, it was $10.25 \pm 1.3(\mathrm{gm} \%)$. No significant difference in hemoglobin level at delivery in two groups was seen (Table 3).

In this study, the mean duration of third stage of labour in study group was $6.92 \pm 1.54$ minute and in control group, it was $8.71 \pm 1.66$ minute. Significant difference was seen in the mean duration of third stage of labour in both the groups $(\mathrm{p}<0.05)($ Table 4$)$.

Table 4: Comparison of duration of third stage of labour in both groups.

\begin{tabular}{|llll|}
\hline Duration of third stage of labour (minute) & Study & Control & p value \\
\hline Mean \pm SD & $6.92 \pm 1.54$ & $8.71 \pm 1.66$ & $<0.0001$ \\
\hline Median & 6.57 & 8.5 & \\
\hline Inter quartile range & $6.133-7.400$ & $7.675-9.358$ & \\
\hline
\end{tabular}

In this study in study group, the mean blood loss during third stage of labour was $110 \mathrm{ml}$ and in control group it was $160 \mathrm{ml}$. The mean blood loss during third stage of labour in both group was significant $(\mathrm{p}<0.05)$. In control group $10(7.94 \%)$ patients were having blood loss of more than $200 \mathrm{ml}$ out of which 2 patients were having post-partum hemorrhage. In study group none of the patient developed postpartum hemorrhage (Table 5). 
A total $1(1.59 \%)$ patients needed blood transfusion in study group while $2(3.17 \%)$ patients needed blood transfusion in control group. No significant difference in two groups was seen $(\mathrm{p}>0.05)$ (Table 6).

Table 5: Comparison of blood loss $(\mathrm{ml})$ during third stage of labour in both groups.

\begin{tabular}{|lllll|}
\hline & & Group 1 & Group 2 & Total \\
\hline \multirow{3}{*}{$\begin{array}{l}\text { Blood loss } \\
(\mathrm{ml})\end{array}$} & $50-100$ & $30(48 \%)$ & $8(13 \%)$ & $38(30.16 \%)$ \\
\cline { 2 - 5 } & $101-150$ & $27(43 \%)$ & $19(30 \%)$ & $46(36.51 \%)$ \\
\cline { 2 - 5 } & $151-200$ & $6(10 \%)$ & $26(41 \%)$ & $32(25.40 \%)$ \\
\hline Total & 200 & $0 \%$ & $10(16 \%)$ & $10(7.94 \%)$ \\
\hline Mean \pm SD & $63(100.00 \%)$ & $63(100.00 \%)$ & $126(100.00 \%)$ \\
\hline Median & $112.46 \pm 27.3$ & $170.32 \pm 83.11$ & $<0.0001$ \\
\hline Inter quartile range & 110 & 160 & \\
\hline
\end{tabular}

Table 6: Need of blood transfusion in participants.

\begin{tabular}{|lllll|l|}
\hline \multirow{2}{*}{ Need for blood transfusion } & & Study & Control & Total & p value \\
\cline { 2 - 5 } & Yes & $1(1.59 \%)$ & $2(3.17 \%)$ & $3(2.38 \%)$ & \multirow{2}{*}{1.000} \\
\cline { 2 - 5 } Total & No & $62(98.41 \%)$ & $61(96.83 \%)$ & $123(97.62 \%)$ \\
\hline
\end{tabular}

\section{DISCUSSION}

Prolongation of the third stage of labour leads to an increased likelihood of maternal morbidity and mortality and its related complications, which include uterine atony, retained placenta, postpartum hemorrhage (PPH), hemorrhagic shock, and even maternal death. ${ }^{5}$ Placental delivery is essential in allowing the uterus to contract and decrease blood loss during the third stage. Placental cord drainage is likely to decrease placental volume and surface area that might facilitate placental separation and uterine contraction, which results in a further increase of the separated area. This facilitates early placental delivery and a shortening of the third stage duration. ${ }^{6}$ The risk of $\mathrm{PPH}$ increases if the placenta is not delivered within 10 minutes. ${ }^{7}$ placental blood has been recommended for active management of third stage by many obstetricians to facilitate the delivery of the placenta in vaginal deliveries. $^{8}$

Some studies showed placental cord drainage is effective in reducing the duration of third stage of labour with placental cord drainage. Sharma et al, Giacalone et al, Gulati et al, found that the mean difference in duration of third stage of labour between placental drainage group and control group was $5.33 \mathrm{~min}, 7 \mathrm{~min}$, and $2.78 \mathrm{~min}$ and which was statistically significant..$^{8-10}$ Roy et al and Metin et al found the same results. ${ }^{11,12}$ The Cochrane database of systemic reviews concluded that cord drainage results in statistically significant reduction in the length of the third stage of labor. ${ }^{13}$ In this study the mean difference in duration of third sage of labour between placental cord drainage group and control group was 1.79 minutes which was statistically significant.
Gulati et al showed mean difference in blood loss of third stage of labour between placental cord drainage group and control group was $48.96 \mathrm{ml} .{ }^{10}$ Roy et al showed similar result. ${ }^{11}$ In this study the mean difference in blood loss in placental cord drainage group and control group was $57.86 \mathrm{ml}$ which was statistically significant.

In present study, none of the participants developed postpartum hemorrhage in PCD group compared to two such incidences in control group. In another study by Gulati et al, the incidence of PPH was $6 \%$ in the study group as compared to $12 \%$ in the control group. ${ }^{10}$ There was a statistically significant difference in the incidence of PPH noted by Shravage et al, $3 \%$ in the study group and $10 \%$ in the control group. ${ }^{14}$

Placental retention is defined as the failure of placental delivery within 30 to 45 minutes and it usually requires intervention to assist delivery. ${ }^{15}$ In this study none of the patients had retained placenta in both the groups. Gulati et al observed retained placenta in $4 \%$ in the control group and in $0 \%$ in the study group. ${ }^{10}$ No significant difference was observed between two groups in reference to need for blood transfusion in present. Thus, PCD can be used as a safe and effective method to manage third stage of labour.

There were a few limitations of the study. During blood collection at third stage, some amniotic fluid might enter the collection bag, or there may be omission of blood that spattered on drapes and gowns. Thus, the measurement remains open to inaccuracies that can especially affect the measurement of lower amounts of blood loss. Also, in this study, authors had measured only pre delivery hemoglobin status. Post-partum hemoglobin could not be 
measured in all participants due to technical difficulties and hence not included in analysis. Because of small sample size, this study is limited in its ability to deliver a definitive result and generalize the results to entire population.

Funding: No funding sources

Conflict of interest: None declared

Ethical approval: The study was approved by the Institutional Ethics Committee

\section{REFERENCES}

1. Maswime S, Buchmann E. A systematic review of maternal near miss and mortality due to postpartum hemorrhage. Int J Gynaecol Obstet. 2017;137(1):1-7.

2. Edhi MM, Aslam HM, Naqvi Z, Hashmi H. Post partum hemorrhage: causes and management. BMC Res Notes. BMC Research Notes. 2013;6(1):1.

3. Frolova AI, Stout MJ, Tuuli MG, López JD, Macones GA, Cahill AG. Duration of the third stage of labor and risk of postpartum hemorrhage. Am J Obtet Gynaecol. 2016;127(5):951-6.

4. Jongkolsiri P. Placental cord drainage and the effect on the duration of third stage labour, a randomized controlled trial. J Med Assoc Thai. 2009;92(4):45760 .

5. Leduc D, Vyta Senikas AL. Active management of the third stage of labour: prevention and treatment of postpartum hemorrhage. Clinical practice obstetrics committee. J Obstet Gynaecol Canada. 2010;108(3):258-67.

6. Piphat Jongkolsiri SMM. Placental cord drainage and the effect on the duration of third stage labour, a randomized controlled trial. Dep Obstet Gynecol Fac Med Chulalongkorn Univ Hosp Bangkok, Thailand. 2009;92(4):457-60.

7. Magann EF, Doherty DA, Briery CM, Amy Niederhauser JCM. Timing of placental delivery to prevent post-partum haemorrhage: lessons learned from an abandoned randomised clinical trial. Aust $\mathrm{N}$ Z J Obs Gynaecol. 2006;46(6):549-51.

8. Sharma JB, Pundir P, Malhotra MAR. Evaluation of placental drainage as a method of placental delivery in vaginal deliveries. Arch Gynecol Obs. 2005;271(4):343-5.

9. Giacalone PL, Vignal J, Daures JP, Boulot P, Hedon B, Laffargue F. A randomised evaluation of two techniques of management of the third stage of labour in women at low risk of postpartum haemorrhage. BJOG An Int J Obstet Gynaecol. 2000;107(3):396-400.

10. Gulati N. Chauhan MBRM. Placental blood drainage in management of third stage of labor. J Obstet Gynaecol (Lahore). 2001;51(6):46-8.

11. Roy P, Ambarisha MSS, Bivas B, Anumita B. Placental blood drainage as a part of active management of third stage of labour after spontaneous vaginal delivery. J Obstet Gynecol India. Springer India. 2016;66(1):242-5.

12. Kaba M, Üstün YE, Gül E, Eyİ Y, Tİmur H, Ünlü BS. Placental blood drainage shortens duration of the third stage of labor in women slowly administered 20 IU oxytocin. Gynecol Obstet Reprod Med. 2017;23(1):6-10.

13. Soltani H, Poulose T HD. Placental cord drainage after vaginal delivery as part of the management of the third stage of labour. Cochrane Database Syst Rev. 2011;9:CD004665.

14. Shravage JC, Silpa P. Randomized controlled trial of placental blood drainage for the prevention of postpartum hemorrhage. J Obstet Gynecol India. 2007;57(3):213-5.

15. Magann EF, Evans S, Chauhan SP, Lanneau G, Fisk AD MJ. The length of the third stage of labor and the risk of postpartum hemorrhage. Obs Gynecol. 2005;105(2):290-3.

Cite this article as: Chaudhary M, Shah M, Makwana N. Placental cord drainage during third stage of labour: a randomized control trial at a tertiary care centre. Int J Reprod Contracept Obstet Gynecol 2020;9:1143-7. 